\title{
La traducción y el otro. El acto (invisible) de traducir y los procesos de colonización
}

\author{
Nair María ANAYA FERREIRA \\ Universidad Nacional Autónoma de México
}

\begin{abstract}
A pesar de que suele ser descrita metafóricamente como un puente (lingüístico) entre culturas, a través de la historia la traducción ha desempeñado un papel paradójico no sólo en las relaciones interculturales, sino también como parte de complejos procesos de colonización y conquista. Como resultado, lejos de ser una actividad "inocente", la traducción es resultado de relaciones de poder entre pueblos, culturas, razas y lenguas, por lo que es necesario estudiar las problemáticas relacionadas con los modos de representación que surgen de dichas relaciones. El objetivo de este ensayo es reflexionar, desde una perspectiva poscolonial, acerca de las diversas maneras en las que la traducción (como elemento textual y discursivo) ha intervenido en procesos históricos más amplios (en especial, en la conquista y evangelización de México en el siglo XVI y la expansión imperial inglesa del siglo XIX), y cómo, incluso en el siglo XXI, la difusión de autores extranjeros y la traducción literaria en México están supeditadas a las políticas de publicación de las editoriales extranjeras.
\end{abstract}

PALABRAS CLAVE: traducción y poscolonialismo, traducción e historia, estudios culturales.

In spite of the fact that it is usually metaphorically described as a (lingüistic) bridge between cultures, translation has, throughout history, played a paradoxical role not only in intercultural relations but also as part of complex processes of colonization and conquest. Consequently, far from being an "innocent" activity, translation is the result of power relations established among peoples, cultures, races and languages. It is thus necessary to study the issues which arise from the modes of representation emerging from such relationships. The aim of this essay is to reflect, from a postcolonial point of view, on the ways in which translation (as a textual and discursive element) has taken part in wider historical processes (especially in the conquest and evangelization of sixteenth-century Mexico, and nineteenth-century British imperial expansion) and on how, even in the twentyfirst century, the diffusion of foreign authors and literary translation in Mexico depends on the publication policies of foreign publishing houses.

KEY WORDS: translation and postcolonialism, translation and history, cultural studies. 
A través de los años, las imágenes y percepciones que se tienen de la traducción han hecho hincapié en ciertas características que tienden a borrar la figura misma del traductor y a convertir a esta profesión en una actividad marginal que se limita a reproducir aquello que ha sido dicho o escrito en otra lengua. Y digo profesión no sin una mueca de sarcasmo, pues sabemos muy bien que, para muchos, el acto de traducir puede ser realizado por cualquiera con conocimientos mínimos de una lengua extranjera o bien, en estos tiempos de tecnología y globalización, por ágiles máquinas que, dentro de las mentes mezquinas de algunos, pronto sustituirán a estos personajes tan incómodos y prescindibles: los traductores.

No importa que el resultado de un traductor automático sea una joya literaria como la de las instrucciones que acompañan a un tostador de pan de Hamilton Beach ni que no cumpla con el principio más elemental de cualquier traducción, es decir, la comprensión: "Cómo usar su tostador: enchufe el cordón hacia AC comodidad orificio de salida. Determinado el colores selección en o intermedio selección. Este cuadrante puedo estar determinado hacia elasticidad su encendedor u obscuro tostada". $\mathrm{O}$ bien: "No uso toda otro artificio en o mismo eléctrico receptáculo o toda otra receptáculo por o mismo circuito para sus tostador o él voluntad sobrecarga o circuito o golpe un mecha o circuito cachón".

Incluso cuando reflexionamos sobre una de las representaciones emblemáticas más conocidas, la del traductor como un puente entre culturas, la figura de éste aparece disminuida debido a los criterios que, tradicionalmente, debe seguir: el traductor debe ser un ente invisible que traslada un texto escrito en una lengua extranjera a la lengua meta — en nuestro caso el español— de forma tal que parezca que el texto fue escrito en esa lengua. A esto se agrega también el hecho de que, hasta hace muy pocos años, la traducción no había sido considerada como una disciplina que mereciera no sólo que sus ejecutantes tuvieran estudios formales sino también que fuera objeto de estudio académico. En los últimos treinta o cuarenta años, la creación de carreras universitarias de traducción en nuestro país ha ido resolviendo la primera carencia. Poco a poco se ha ido revirtiendo el viejo patrón que distinguía a los traductores: los traductores no son ya individuos frustrados que al no haber concluido su carrera de abogados, ingenieros o médicos se dedicaban, entonces, a traducir. No, ahora se cuenta ya con traductores profesionales que han hecho una carrera universitaria y que tienen la posibilidad, incluso, de realizar estudios de posgrado en la disciplina dentro de nuestro país.

Sin embargo, la naturaleza misma de la traducción como una actividad práctica que se lleva a cabo, además, en una atmósfera de inmediatez que con frecuencia no nos deja tiempo para pensar en sus repercusiones ha dejado de lado, especialmente en México, el estudio académico de la disciplina, un estudio que nos permita estar plenamente conscientes de la importancia histórica y social de la traducción. Uno de los aspectos que aparece con mayor recurrencia en cualquier disquisición sobre el tema es la relación entre los aspectos formales de la traducción y la dificultad de transmitir lo intangible de la lengua de partida. Es decir, la historia de la traducción ha estado acompañada de debates en los que se trata de concluir qué es lo que constituye una buena traducción en 
términos de su literalidad, fidelidad o alejamiento con respecto al texto original. La relación traductor-texto-lenguas de trabajo parece ser el eje central de esta actividad y, de alguna manera, enmarca el ejercicio de la profesión. Casi por definición, la traducción es una actividad aislada mediante la cual el traductor, como dice Alfonso Reyes, realiza una "tarea humilde y dócil como el servir, y a la vez un peligroso viaje [...] sobre dos caballos de desigual carrera", un viaje en el que el traductor debe mantenerse en equilibrio sin dejar que ningún caballo se desboque (Reyes, 1962: 147).

Solemos estar tan absortos reescribiendo el texto en cuestión, frente a una máquina de escribir o una computadora, rodeados de diccionarios, casi aislados del mundo si no fuera por la prisa de entregar un trabajo que urgía para ayer (y por el cual no sabemos a ciencia cierta cuándo nos van a pagar) que ciertamente no podemos controlar o tener conciencia de las condiciones en que se genera una traducción. Y a pesar de esto, más allá de cada ejercicio individual, la traducción constituye un complejo fenómeno cultural inherente al desarrollo mismo de la civilización y, por lo mismo, es resultado de complejas relaciones de poder entre pueblos, culturas, razas y lenguas.

En consecuencia, el concepto de traducción se convierte en un sitio significativo para discutir, como dice la crítica india Tejaswini Niranjana, problemas de "representación, poder e historicidad" (Niranjana, 1992: 1). Visto desde esta perspectiva, además de ser el ejecutor de la retransmisión de un mensaje, el traductor es también agente integral de complejos fenómenos de aculturación y, por supuesto, de todo proceso de conquista y colonización. Un traductor no es sólo el que sabe dos o más lenguas, sino el receptor de valores culturales e ideológicos que se encarga de generar una nueva cultura a partir de la retransmisión/recreación de una cultura ajena. La posición del traductor puede llegar a ser, entonces, esencialmente política, a pesar de que en muchas ocasiones éste no tenga conciencia de las repercusiones de su papel como tal.

Durante las últimas décadas ha habido un rápido crecimiento de disciplinas teóricas que cuestionan la hegemonía del conocimiento europeo mediante el desenmascaramiento de ciertos principios fundamentales que sostienen a la llamada "civilización occidental". Este cuestionamiento es básicamente interdisciplinario y tiene por objeto desconstruir el bloque monolítico de "Occidente" a través de nuevas propuestas de análisis que ofrecen lecturas diferentes, a partir del margen y la periferia. La traducción no es ajena a todo este movimiento y ha contribuido desde diferentes posiciones, convirtiéndose a la vez en agente y en sujeto de estudio. Así como, por ejemplo, el estudio de las literaturas canónicas se abrió de un paradigma estrictamente estético y moral a interpretaciones que consideraron cada vez más la función política y social del arte hasta llegar a lo que ha sido denominado "Estudios Culturales", de igual manera, la forma de enfocar la traducción cambió radicalmente durante el siglo XX.

Como se puede ver en el índice del Translation Studies Reader, editado por Lawrence Venuti para la editorial Routledge (2000, reimpresión 2003), el tratamiento de la traducción como acto creativo y como disciplina de estudio ha sido objeto de enfoques que van de las reflexiones filosóficas de figuras como Walter Benjamín, Ezra Pound, Jorge Luis Borges y José Ortega y Gasset en las primeras tres décadas del siglo XX, 
pasan por análisis lingüísticos, estilísticos y hermenéuticos de la traducción desde 1940 hasta fines de los años setentas (entre los que se encuentran, por supuesto, la obra de Roman Jakobson, Eugene Nida, J. C. Catford y George Steiner, por mencionar sólo unos cuantos) y, durante los ochentas y los noventas, llegan al campo que se ha llamado "Estudios sobre la traducción" (Translation Studies), expresión que se emplea para describir "el estudio de los procesos de traducción más allá de lo puramente lingüístico [...] y [que] están estrechamente vinculados a los estudios interculturales, dado que su objetivo es analizar sistemáticamente los procesos de transferencia de TEXTOS a través de límites culturales, y las consecuencias que esa transferencia tiene tanto en el SISTEMA de partida como en el de llegada" (Bassnett, 2002: 224).

Los "Translation Studies" han girado alrededor de tres grupos de investigación: el primero, de Itamar Even-Zohar y Gideon Toury de Tel Aviv, teoriza a la literatura como un "polisistema" compuesto por formas y cánones interrelacionados que generan ciertas "normas" que restringen las estrategias y las posibilidades de elección del traductor. El énfasis recae en el sistema meta, por lo que las traducciones literarias constituyen hechos de dicho sistema. El segundo, en Holanda y Bélgica, incluye a teóricos como James Holmes y André Lefevere, y considera a la traducción como una forma de reescritura inscrita dentro del contexto más amplio del fenómeno literario, como parte de otros aspectos textuales que incluyen la crítica, la edición y la historiografía literaria. El tercero se centra en Inglaterra y se consolida gracias a la obra de Susan Bassnett, quien explora las consecuencias ideológicas de la traducción, sobre todo en los países de habla inglesa, y analiza la forma en que las políticas culturales dictan en gran medida qué textos son traducidos, cómo y por qué.

Los dramáticos cambios en el campo de los estudios sobre la traducción ocurren de forma paralela a otros replanteamientos teóricos y culturales, como el de los estudios poscoloniales, es decir, ese enorme y variado corpus - tanto de carácter literario como teórico y crítico - que articula problemáticas surgidas del imperialismo europeo (en especial el británico) y de sus repercusiones en las naciones que se independizaron por ahí de la década de los sesentas.

Dentro de este contexto, la traducción desempeña varias funciones, relacionadas, sobre todo, con uno de los ejes fundamentales del poscolonialismo: reconocer que el imperialismo y el colonialismo tuvieron un carácter textual y discursivo que sustentó e incluso justificó otros aspectos más evidentes como la expoliación económica y la apropiación política. Por un lado, constituye uno de los instrumentos con los que se confronta la alteridad, una alteridad que, paradójicamente, ha servido para crear sentidos universales de la identidad al tiempo que rompe otros individuales. En segundo lugar, se convierte en un eje fundamental del desarrollo de la historia y, dentro de los diversos procesos de expansión imperial que han determinado la configuración del mundo moderno, se transforma en un ejercicio de poder mediante el cual se genera una circunstancia histórica que trasciende, por mucho, la voluntad individual.

Una aportación significativa de la teoría poscolonial es haber reconocido explícitamente que el fenómeno imperial se fundamentó en gran medida en la textualidad, 
es decir, en operaciones discursivas que incorporaron al sujeto colonial dentro de un sistema de representación mediante el cual se legitimaron los intereses y las acciones de los poderes dominantes en un momento dado. El hecho, en apariencia simple, de volver a bautizar el lugar conquistado o apropiado constituía una manifestación de autoridad imperial que borraba, de tajo, parte de la historia de dicho lugar y establecía una primera ruptura entre los habitantes originales y su entorno. Como dice Louis-Jean Calvet en Lingüistica y colonialismo, el "derecho a nombrar es la vertiente lingüística del derecho a usurpar" (1981: 55). El acto de renombrar conllevó un proceso encubierto de traducción: ya fuera que se transcribieran los nombres autóctonos mediante similitudes fonéticas o bien que se denominara a alguna región por asociación sinecdóquica o bien que se trasladara la toponimia europea a la nueva geografía. En cualquier caso, la traslación no sólo constituía una demostración de poder efectivo (económico o militar), sino que también establecía jerarquías lingüísticas en donde el predominio de una lengua sobre otra(s) marcaba las diferencias culturales que con el tiempo determinaron la hegemonía europea.

Las dos primeras formas de traducción, la transcripción fonética y la denominación por sinécdoque producen una especie de intersticio semántico por el que se producen las primeras distorsiones en la percepción cultural del Otro, al tiempo que se cimientan muchos de los valores del poder dominante. Calvet insiste en que la falta de un esfuerzo real por comprender al otro (evidente, incluso, en el simple hecho de intentar lograr una transcripción pertinente) conlleva una especie de desprecio implícito. Así, varias de las denominaciones con las que conocemos a los indios del norte de América no son más que transcripciones equivocadas: los siux, por ejemplo, adquieren su gentilicio gracias a una "deformación de la pronunciación francesa (nadouessioux) de la palabra que en chippewa servía para designarlos" (Calvet, 1981: 55). Los lenilapes ("pueblos del inicio") fueron bautizados con el nombre del inglés Thomas West de la Warr y se convirtieron en los delaware, mientras que Camerún no es más que la adaptación castellana del apelativo con que los portugueses denominaron a la región del río Wuri: rio dos camerroes, río de los cangrejos (1981: 55-56). En nuestro propio contexto basta recordar la forma en que el nombre náhuatl de la ciudad de la eterna primavera, Quauhnáhuac, se convirtió, asombrosamente, en Cuernavaca y perdió así las connotaciones simbólicas de la región — como el lugar de los buenos brujos-que Malcolm Lowry aprovechó magistralmente para su novela Bajo el volcán.

Un ejemplo de la formas en las que el fenómeno colonial dependía de la textualidad y la discursividad es precisamente el de la cartografía y la toponimia. Como ha analizado Elleke Boehmer en Colonial and Postcolonial Literature, en la medida en que los europeos trazaban las características de una región inexplorada en un mapa, el conocimiento expresado en papel se convertía en justificante para apropiarse de dicha región, entre otras razones, porque los datos proporcionados en la carta geográfica funcionaban, de hecho, a modo de palimpsesto en el que la vida y los valores culturales del primer espacio eran borrados y cubiertos por las inscripciones importadas de Europa. Así, los mapas coloniales se llenaron de las viejas toponimias aplicadas a 
las nuevas geografías: Nueva York, Valladolid, Nueva España. Renombrar constituía un acto extremo y arbitrario de traducción a la vez que una forma de apropiación en la que los recién llegados recreaban y reconstruían la experiencia simbólica del viejo mundo. Renombrar establecía también un marco temporal sincrónico para las colonias: a pesar de no ser Europa, de no ser Inglaterra, de no ser España, el nombre del lugar declaraba que se tenía una relación indisoluble con el "Viejo Continente" y, de alguna forma, que esta relación era de sumisión o, cuando más, de un parentesco jerárquico en el que la metrópolis desempeñaba un papel paternalista en relación con los "nuevos" territorios (1995: 13).

Este proceso ¿inconsciente? de traducción trajo consigo otros más en los que no se puede negar ya una premeditación por parte de los funcionarios imperiales, fueran éstos laicos o religiosos, católicos o protestantes. En el caso mexicano, la traducción - en una variedad de manifestaciones - constituyó, quizá, la actividad central tanto en la evangelización como en la aculturación de los pueblos indígenas, al grado que podemos considerarla como un producto cultural sobre el que su agente o mediador, el traductor, careció de poder de determinación. Pensemos en dos instancias específicas que nos servirán como punto de partida para comparar la función de la traducción en dos momentos históricos diferentes: la conquista española del siglo XVI y la expansión imperial inglesa del XIX.

Durante los momentos iniciales de la colonización española, en especial a partir de 1524 con la llegada de los doce frailes franciscanos, la traducción tomó dos vertientes que culminaron en la conversión espiritual de los indios. En primer lugar, los frailes se vieron obligados a aprender una o dos lenguas indígenas con el fin de comprender las costumbres locales y poder así comunicarse con los indios. La urgente necesidad de llevar esto a cabo se debió a la incapacidad de los primeros intérpretes de traducir las entrevistas iniciales entre los frailes y los pocos sabios aztecas que habían sobrevivido la conquista. Conscientes de que los intentos por evangelizar a la elite mexica habían fracasado debido a que los intérpretes indios no habían podido traducir los complejos conceptos teológicos de ambas culturas, los españoles se percataron de que debían traducir al náhuatl y a las otras lenguas los dogmas cristianos. Quedó de manifiesto la primera regla de la traducción: no basta con conocer las palabras de una segunda lengua, hay que conocer a fondo su contexto cultural.

Un fraile llamado Jacobo de Testera ideó una compleja estrategia que incluso hoy en día no ha sido comprendida del todo. Esta estrategia constituye un ejemplo del acto de traducir llevado al extremo, un acto en el que, asombrosamente, se logran "equivalencias dinámicas" como las sugeridas por Nida al mismo tiempo que se permiten interpretaciones de textos religiosos que en la España de 1560 habrían sido consideradas verdaderas herejías. Los llamados catecismos testerianos son, en realidad, códices o, como los llama Joaquín Galarza, el investigador que los ha dado a conocer, "manuscritos pictográficos". Es decir, Jacobo de Testera decidió emplear el material y las convenciones indígenas como primer paso para su traducción: tiras de papel con imágenes a las que posteriormente se les añadieron leyendas en latín, caste- 
llano o náhuatl. ${ }^{*}$ Pero además emblematizó ciertos conceptos que resultaban ajenos al original latín o castellano: el pecado venial es representado como un "pequeño reptil o saurio de lengua trífida, cuerpo estriado y cuatro patas con garras". El Mal como un "monstruo con cuernos, lengua trífida, escamas, llamas, dos alas llenas de ojos, cuatro patas con garras y larga cola" o también "con dos brazos y manos, ojos en las piernas, dos patas con garras y gran cola de serpiente" (en Catelli, 1998: 173).

La explicación que se da de esta atrevida traducción pictográfica es que sólo se podía permitir en caso de que se creyese que la lengua a la que "se está traduciendo carece de contenido propio y que por lo tanto no reviste ningún tipo de amenaza semántica real para el original" (Catelli, 1998: 173).

Cito aquí la traducción de la pictografía del Padre Nuestro:

¡Oh, Nuestro padre venerado!

En el cielo, nuestro padre venerado está.

El notable venera el santo nombre de Jesús.

El hombre pide sobre la tierra

el reino (que está) en el cielo.

Que sobre la tierra nuestro padre venerado aspire la gloria, y en

el universo cristiano las flores se multipliquen.

Los fieles reciben, de rodillas,

la tortilla que nuestro padre venerado les da, cada día cristiano.

Los fieles toman sus alimentos.

Que nuestro padre venerado muestre el pecado venial

a los fieles, que vienen hacia él,

con recogimiento.

Nuestro padre venerado muestra el pecado venial a los fieles, que van hacia él, con recogimiento.

Que los fieles vayan, con recogimiento, hacia nuestro padre venerado, que mira al alma vencida por el pecado mortal.

Que nuestro padre venerado defienda y proteja, con la espada y la cruz, a los fieles afligidos y atemorizados; que le van a pedir protección del Maligno,

que temeroso

huye.

Que la flor sea.

Se puede ver aquí ya la forma en que la mentalidad indígena fue gradualmente transformada mediante un elaborado proceso de traducción (en Catelli, 1998: 174-175).

La segunda vertiente que tomó la traducción en la conversión espiritual de los indios fue a la inversa. La Corona española autorizó en 1536 la creación del famoso Colegio de Santa Cruz de Tlatelolco, donde un pequeño número de nobles y niños indígenas

\footnotetext{
* El llamado "Catecismo Testeriano" puede ser consultado en la Biblioteca Digital Mundial en http://www.wdl.org/es/item/2964/pages.html\#volume/1/
} 
aprendieron latín y español, así como gramática, retórica, música, religión, filosofía e incluso medicina mexicana. El Colegio tenía un propósito muy claro: adiestrar a instructores indígenas para que enseñaran las doctrinas cristianas al resto de la población en su propia lengua. Los objetivos y resultados del Colegio fueron notables, pues en pocos años varias generaciones de estudiosos indígenas contribuyeron a realizar las primeras investigaciones etnográficas, a traducir fragmentos de la Biblia y otros textos litúrgicos a las lenguas locales, y a traducir al español muchas de las tradiciones y costumbres autóctonas (las cuales serían registradas meticulosamente años más tarde por fray Bernardino de Sahagún).

Sin embargo, el hecho mismo de adquirir lenguas impuestas y de emplearlas con soltura y erudición puede convertirse, como sucedió también siglos después en África, en una forma de resistencia amenazante para el poder central. Algunos españoles se sintieron amedrentados por los brillantes alumnos trilingües del Colegio de Santa Cruz y éste fue clausurado en la década de los cincuentas del siglo XVII. La traducción desempeñó una función paradójica, a la vez de rescate y supresión de la cultura precortesiana. Si bien es cierto que la transcripción y traducción de los códices y del conocimiento oral fue la forma de sobrevivencia del legado indígena, también es verdad, como lo ha analizado Miguel León-Portilla, que el transvase conllevó una distorsión, por leve que fuera, del original, ya sea por la contaminación cultural implícita en la doble visión de los escribas o bien porque la oralidad, "siempre abierta a enriquecimientos y adaptaciones en las diversas circunstancias, no puede ser convertida en algo totalmente extraño a la cultura original. Tal transformación no coincide con los procedimientos mentales asociados a la visión indígena del mundo" (León-Portilla, 1996: 22-23).

En cuanto al conocimiento traducido al español, por así decirlo, institucionalmente, éste también fue considerado por las autoridades eclesiásticas e imperiales como una peligrosa forma de rebelión. Los esfuerzos de Sahagún fueron vistos como un plan perverso para perpetuar un repulsivo universo pagano y su obra quedó confiscada en la década de los setentas del siglo XVII. Sahagún, el estudioso y traductor, se convirtió, entonces, en un individuo subversivo.

La recopilación del saber vernáculo por parte de los frailes españoles y los primeros indios conversos forma parte de un complejo entramado cultural en el que se gestan, simultáneamente, los brotes de resistencia y los de hegemonía sociopolítica. Los primeros suelen quedar ocultos o en estado latente, esperando una ocasión propicia para salir a la superficie, mientras que los segundos se concretan, con el paso de los años, en una ideología que, finalmente, incorpora al sujeto colonial dentro del discurso dominante. En consecuencia, la traducción forma parte de los mecanismos centrales de la dominación colonial, a pesar de que estrictamente hablando, en el caso de la evangelización, más que traducción lo que se logró, como dice Luis Villoro, fue una "duplicación del mundo", un acoplamiento gráfico, iconográfico y escriturario de dos mundos diferentes (en Catelli, 1998: 211).

No conocemos con certeza los escrúpulos que pudieron haber tenido los traductores indígenas al realizar su labor, así como tampoco conocemos el grado en que los 
frailes ejercieron algún tipo de censura o si tuvieron reparos en la realización de su titánica tarea. Lo que sí sabemos es que la labor traslaticia es un factor primordial en cualquier tipo de discurso colonial, pues por medio de la traducción se acota y contiene el conocimiento autóctono, es decir, se cumple con la primera etapa del control ideológico subyacente en todo proceso de conquista.

Este rol paradójico de la traducción, tan alejado de la imagen idealizada de dicha actividad como puente intercultural, fue aún más evidente durante la expansión británica de los siglos XVIII y XIX. Como lo han demostrado varios críticos poscoloniales, la traducción fue un ejercicio institucional, de tipo político e ideológico, que contribuyó a la gran empresa imperialista mediante la incorporación y transformación intencional del saber de los pueblos colonizados. En la India, el Medio Oriente y el sureste asiático, la traducción de textos legales, religiosos o mitológicos fue un objetivo primordial de los colonizadores, quienes buscaban en los textos locales los elementos necesarios para ayudarlos a gobernar. Como lo plantea Elleke Boehmer, los ingleses procuraron incluso la cooperación de las elites colonizadas con el fin de legitimar el gobierno colonial; es decir, los estudiosos orientales (que no, todavía, orientalistas en ese momento) proporcionaron los textos a los funcionarios británicos y los ayudaron a interpretarlos, sin percatarse, quizá, de que entregaban también el germen que con el tiempo llegaría a corroer los cimientos de su propia cultura.

Desde la obra crítica fundacional de Edward Said, Orientalismo (1978), hasta los debates de los más recientes analistas del discurso colonial, se ha estudiado a profundidad el grado de conversión ideológica, tanto para los colonizados como para los colonizadores, que significó traducir las obras clásicas de cada región. En primer lugar, la transcripción lingüística, la recopilación de gramáticas y la traducción constituyeron prácticas de neutralización, estandarización y regulación, por así decirlo, del conocimiento exótico. Al codificar dicho conocimiento se le aplicaban las estructuras europeas y, de una forma o de otra, se le incorporaba al discurso aceptado de las instituciones académicas y políticas europeas, mediante el empleo de las prácticas de representación occidentales. En segundo lugar, el proceso de traslación conllevaba también juicios de valor que calificaban la otredad no sólo en términos de superioridad e inferioridad culturales, sino en función de una calidad moral que, por necesidad, era depravaba y corrupta ante la mirada europea. Desde esta perspectiva, las nuevas versiones de los textos originales cumplían con el propósito de identificar los elementos "estables" de sociedades que eran, por definición, inestables y volátiles, lo cual, a su vez, les permitía "fijar" ciertas características como típicas de la cultura en cuestión. Este proceso justificaba, entonces, las libertades en el acto de traducción. Niranjana cita una frase del célebre traductor del Rubayata, Edward Fitzgerald, quien en 1851 comentó: "Me entretiene tomar cuantas libertades quiera con estos persas que (creo) no son tan poetas como para asustarlo a uno y alejarlo de dichas excursiones y quienes en realidad necesitan un poco de arte para darles forma" (Niranjana, 1992: 58-59). En tercer lugar, la traducción servía como la primera (y muchas veces única) introducción de la cultura exótica para los británicos pero también, paradójicamente, para los sujetos coloniales 
que ahora hablaban inglés y que quedaban, así, incorporados de modo definitivo en un proceso de representación ante el que tenían pocas posibilidades de responder.

En "Los traductores de Las mil y una noches", Borges anticipa por varias décadas esta preocupación poscolonial y nos deja ver la forma en que los europeos absorbieron y distorsionaron la cultura del Medio Oriente. Como nos dice Borges, con su ironía sutil, el capitán Richard Francis Burton, cónsul británico en Trieste, decidió traducir esta compleja obra con el propósito de aniquilar a uno de sus rivales, Edward Lane, reconocido orientalista que, a su vez, había realizado una meticulosa traducción de los famosos cuentos para suplantar una versión anterior, en francés, hecha por Jean Antoine Galland, un arabista que había dejado marcado el libro árabe en la mente europea. Según Borges, Coleridge, Thomas de Quincey, Stendhal, Tennyson, Edgar Allan Poe y Newman, todos, leyeron esa versión, a pesar de que era la peor escrita y, de hecho, estaba llena de adaptaciones inspiradas, como dice Borges, por el decoro del siglo XVIII.

Tenemos aquí tres visiones sobre la traducción que dicen más de una hegemonía cultural que del proceso estricto de traducir. Galland disfruta el acto mismo de narrar y, en su deseo de transmitir una noción de urbanidad que se adaptara a los valores de su tiempo, domestica a los árabes para que sean bien aceptados en París. Lane, en cambio, ofrece una versión erudita que, detrás de comentarios aparentemente enciclopédicos, no hace más que mutilar y censurar temas no aptos para los lectores ingleses con comentarios como "suprimo una explicación repugnante" o "la historia del esclavo Bujait del todo inapta para ser traducida" (Borges, 2002: 122). Richard Burton, por su parte, decide ser absolutamente literal y, a pesar de que su pobre versificación rompe con esa intención, logra transmitir todo lo que Lane había omitido mediante la elaboración de glosas y notas (más de trescientas en el volumen seis, nos dice Borges) y el empleo de un vocabulario que no tiene ninguna correspondencia con el original en árabe.

Sin embargo, una de las grandes preocupaciones teóricas de los traductores de hoy en día nunca afectó, realmente, a ninguno de estos traductores: ¿puede la traducción producir el mismo efecto que el texto fuente tuvo en sus lectores originales? Como bien dice Borges, Las mil y una noches es una adaptación de viejos relatos dirigidos a una audiencia iletrada, que creía en maravillas remotas, vulgar y propensa a la exageración. ¿Cómo podían entonces recibirla los respetables caballeros del West End londinense, sentados en su distinguido club, fumando pipa, preocupados por su erudición y mostrando desdén con su flema británica?

En realidad, nunca importó pues, como discutió hasta el cansancio Edward Said en su Orientalismo, la creación de esta imagen del Medio Oriente no fue más que un complejísimo constructo cultural por medio del cual Europa (nosotros) se enfrentó y domesticó al otro y forjó su identidad hegemónica.

El mismo Borges padeció un proceso similar. Como dice Lawrence Venuti, en su libros Scandals of Translation, a raíz del boom de la literatura latinoamericana en el mundo de habla inglesa, surgió una mayor inquietud por traducir a autores como Borges, quien entre 1967 y 1972 trabajó en colaboración con el traductor estadounidense Norman Thomas di Giovanni. Pero antes de seguir adelante hagamos un paréntesis. 
¿Qué fue en realidad el boom latinoamericano sino el reconocimiento por parte del público lector europeo y estadounidense del valor de la literatura de nuestro continente? (Independientemente, por supuesto del valor intrínseco de ésta.) Curiosamente, el boom coincide también con el periodo (fines de los cincuentas, la década de los sesentas) en que las editoriales se abrieron también a la obra de los escritores africanos, indios, caribeños, escritores de la periferia que "traducían" a través de la literatura la realidad de sus lejanos países al público europeo. Es decir, Europa y Estados Unidos se encontraban en un periodo en el que se podían abrir a otros Otros.

En este contexto, la anécdota sobre Borges adquiere una dimensión representativa, una vez más, del poder oculto de la traducción y de la fuerza silenciosa de ciertos valores culturales. Para el traductor di Giovanni dar a conocer a Borges significaba también incrementar su accesibilidad a los lectores estadounidenses y para esto era necesario asimilar los textos castellanos a los "cánones estilísticos de Estados Unidos, adhiriéndose al uso estándar, suavizando las abruptas transiciones de la prosa borgiana, usando una dicción concreta para evitar abstracciones e incluso corrigiendo las referencias intertextuales que Borges sacaba de su memoria [...] lo que buscaba era reprimir las peculiaridades literarias de la innovadora escritura de Borges, ejerciendo una actitud antiintelectual en la traducción de un autor completamente intelectual" (Venuti, 1998: 4). Por supuesto, Borges decidió cancelar el trabajo conjunto después de cuatro años.

Se puede decir que, vistos con frialdad, muchos de estos fenómenos lingüísticos, literarios y culturales son tan amplios y complicados que de ninguna manera pueden atribuirse a un solo individuo y, mucho menos, a un traductor. Se puede decir también que muchos de los ejemplos mencionados a lo largo de este ensayo son instancias demasiado radicales de traducción como para tomarlas en serio. Sin embargo, creo que no está por demás detenerse en nuestras actividades cotidianas para reflexionar acerca de los efectos de estos elaborados procesos de traducción histórico/cultural sobre nuestra identidad contemporánea.

De hecho, para algunos críticos poscoloniales la traducción como fenómeno social constituye una metáfora de las inequitativas relaciones de poder que definen la condición misma del individuo colonizado. De acuerdo con Bhabha, los individuos que han experimentado alguna forma de colonización ( $\mathrm{y}$ esta definición abarca prácticamente a todos los que vivimos en países del llamado "Tercer Mundo") viven, por así decirlo, en "un estado de traducción" no sólo porque gran parte del conocimiento científico y cultural necesario para sobrevivir proviene de países más avanzados sino también porque, en la actualidad, muchos de ellos han sido arrancados de sus países de origen $\mathrm{y}$ viven como migrantes o exilados (Bhabha, 1994).

Este sentimiento, que nos resulta bien conocido, se percibe a flor de piel en la obra de escritores y críticos de países que obtuvieron su independencia en la década de los sesentas. Las reacciones que ellos han tenido frente al llamado "canon occidental" y frente al dilema de estar empleando la lengua impuesta del "colonizador" dependen directamente de los procesos amplios de traducción de los que he estado hablando y sirven como punto de partida de una reconsideración de nuestro legado cultural: nuestra 
condición mestiza y sincrética no tiene que ver sólo con cuestiones de raza sino que es resultado de un larguísimo proceso de aculturación y transculturación que incluyó, por supuesto, el adentrarse cada vez más en la cultura europea y conocer de cerca sus expresiones artísticas y literarias. Para nosotros esto es tan obvio que, en términos generales, creo que no nos cuestionamos si debemos hablar español y si tenemos un acceso relativamente fácil a las obras literarias, artísticas, musicales de Europa y Estados Unidos. En la primera década del siglo XXI somos resultado de más de cinco siglos de relaciones interculturales con Europa y de una política educativa que ve hacia la universalidad. Después de todo, para Vasconcelos, la traducción fue también el eje central de su proyecto educativo y de su ambiciosa gesta, para que los grandes clásicos de la literatura universal estuvieran al alcance de todos.

Sin embargo, esto ha significado también que nuestro propio desarrollo cultural (y por qué no decirlo, histórico) ha estado determinado en gran medida por el canon "occidental" y esta condición continúa marcando qué leemos y por qué. En ese sentido, la situación del traductor literario en México es muy poco propicia, pues se ve afectada por los fuertes intereses económicos que dominan el mundo editorial. Las editoriales mexicanas no pueden competir con las editoriales españolas, que son las que acaparan la publicación de obras recientes en una gran cantidad de lenguas. Esto influye en las alternativas de lectura que se ofrecen aquí en México.

Casi igual que en la Colonia o en el siglo XIX, los lectores actualmente están supeditados a leer las obras y a los autores que forman parte de un canon central, por muy reciente que sea éste. Así, es posible encontrar en las librerías del país la obra de José Saramago, de Gunther Grass o de Milan Kundera, grandes favoritos de las elites intelectuales de nuestro país. No obstante, si uno busca obras un poco más periféricas de autores canadienses, africanos, caribeños, asiáticos o australianos, sean éstos de expresión inglesa o francesa, por no mencionar los libros de japoneses, chinos, brasileños o de otra nacionalidad, resulta verdaderamente frustrante.

Hay un ejemplo curioso que ayuda a ilustrar esta situación. En 2001 el ganador del Premio Nobel de Literatura fue el escritor V. S. Naipaul, nacido en Trinidad, de origen hindú y formado en la tradición inglesa (de hecho Naipaul vive en Inglaterra desde los dieciocho años, es decir, hace más de cincuenta años). Como parte de las entrevistas rutinarias que se hacen a otros intelectuales acerca de dicha designación, Augusto Roa Bastos comentó: "Estoy contento de que hayan premiado a un escritor poco conocido, lo cual es una manera de promover la literatura de esa gente que viene de lejos y tiene una experiencia distinta a la nuestra. Hay que aplaudir cuando distinguen a alguien que no está en el mercado de las letras" (Reforma, 2001: 1c). Y eso que Naipaul es considerado el escritor "inglés" más importante de la segunda parte del siglo XX.

Lo que hay detrás de esto tiene que ver con lo que acabo de mencionar. El mercado editorial de España tiene estrategias restringidas en cuanto a los escritores "extranjeros" que dejan suficientes ganancias. Salman Rushdie sólo fue redituable después de la fatwa. Michael Ondajee cuando se volvió popular por la adaptación cinematográfica de su obra. También, por desgracia, las editoriales mexicanas no pueden competir en la 
compra de derechos y demás procedimientos del mercado editorial El resultado es la inaccesibilidad a obras literarias de gran calidad que no entran en los criterios de selección editorial.

Esta situación, sin embargo, no nos impide reflexionar sobre la necesidad de abrir nuevos campos de interés y sobre el reto que implica asumir nuestra labor traductora, pues la traducción desempeña un papel central en las construcciones culturales y en el desarrollo mismo de los acontecimientos culturales.

\section{Obras citadas}

BASSNETT, Susan. 2002. “Estudios de traducción”. Entrada en Michael PAYNE, ed. 2002. Diccionario de teoría crítica y estudios culturales. Buenos Aires: Paidós.

BHABHA, Homi. 1994. The Location of Culture. Londres: Routledge.

BOEHMER, Elleke. 1995. Colonial and Postcolonial Literature. Oxford: Oxford University Press.

BORGES, Jorge Luis. 2002. "Los traductores de las 1001 noches". Historia de la eternidad (1936, 1974). Madrid: Alianza Editorial.

CALVET, Louis Jean. 1981. Lingüistica y colonialismo. Madrid: Ediciones Júcar.

CATELLII, Nora y Marietta GARGatAGLI. 1998. El tabaco que fumaba Plinio. Escenas de la traducción en España y América: relatos, leyes y reflexiones sobre los otros. Barcelona: Ediciones del Serbal.

Galarza, Joaquín. 1992. Códices testerianos-Catecismos indígenas. México: Tava Editorial.

LeÓn-Portilla, Miguel. 1996. Del destino de la palabra. De la oralidad y los glifos mesoamericanos y la escritura alfabética. México: FCE.

NiRANJANA, Tejaswini. 1992. Siting Translation. History, Post-structuralism, and the Colonial Context. Berkeley: University of California Press.

Reforma, viernes 21 de octubre de 2001, Sección C, Cultura, p. 1c.

REYES, Alfonso. 1962. "De la traducción". Obras completas: La experiencia literaria. México: FCE. (Letras Mexicanas, 14)

VenUTI, Lawrence, ed. 2003. The Translation Studies Reader. Londres: Routledge. . 1998. The Scandals of Translation. Towards an Ethics of Difference. Londres: Routledge. 